\title{
Early Evidence of Dose-dependent Pharmacodynamic Activity Following Treatment with SY-5609, a Highly Selective and Potent Oral CDK7 Inhibitor, in Patients with Advanced Solid Tumors
}

\author{
Kyriakos P. Papadopoulos \\ South Texas Accelerated Research Therapeutics \\ Manish R. Sharma \\ South Texas Accelerated Research Therapeutics \\ Erika Hamilton \\ Sarah Cannon Research Institute/Tennessee Oncology \\ Pepra Richardson \\ sollow this and additional works at: htths:///dc.jefferson edu/medoncposters \\ Part of the Oncology Commons \\ Babar Bashir nowh hestiv access to this document benefits you
}

\footnotetext{
Recommended Citation

See next page for additional authors
Papadopoulos, Kyriakos P.; Sharma, Manish R.; Hamilton, Erika; Richardson, Debra; Bashir, Babar; Juric, Dejan; Shapiro, Geoffrey; Hodgson, Graeme; Ke, Nan; D'Ippolito, Anthony; Johannessen, Liv; Kang-Fortner, Qing; Zhou, Li; Rosario, Maria; Zamboni, William; Jolin, Hina A.; Madigan, Catherine; Kelly, Michael J.; and Roth, David A., "Early Evidence of Dose-dependent Pharmacodynamic Activity Following Treatment with SY-5609, a Highly Selective and Potent Oral CDK7 Inhibitor, in Patients with Advanced Solid Tumors" (2020). Department of Medical Oncology Posters. 12.

https://jdc.jefferson.edu/medoncposters/12

This Article is brought to you for free and open access by the Jefferson Digital Commons. The Jefferson Digital Commons is a service of Thomas Jefferson University's Center for Teaching and Learning (CTL). The Commons is a showcase for Jefferson books and journals, peer-reviewed scholarly publications, unique historical collections from the University archives, and teaching tools. The Jefferson Digital Commons allows researchers and interested readers anywhere in the world to learn about and keep up to date with Jefferson scholarship. This article has been accepted for inclusion in Department of Medical Oncology Posters by an authorized administrator of the Jefferson Digital Commons. For more information, please contact: JeffersonDigitalCommons@jefferson.edu.
} 


\section{Authors}

Kyriakos P. Papadopoulos, Manish R. Sharma, Erika Hamilton, Debra Richardson, Babar Bashir, Dejan Juric, Geoffrey Shapiro, Graeme Hodgson, Nan Ke, Anthony D'Ippolito, Liv Johannessen, Qing Kang-

Fortner, Li Zhou, Maria Rosario, William Zamboni, Hina A. Jolin, Catherine Madigan, Michael J. Kelly, and David A. Roth 


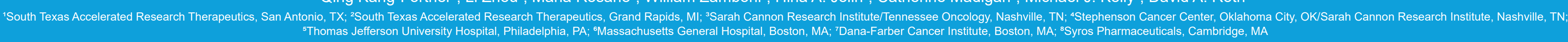

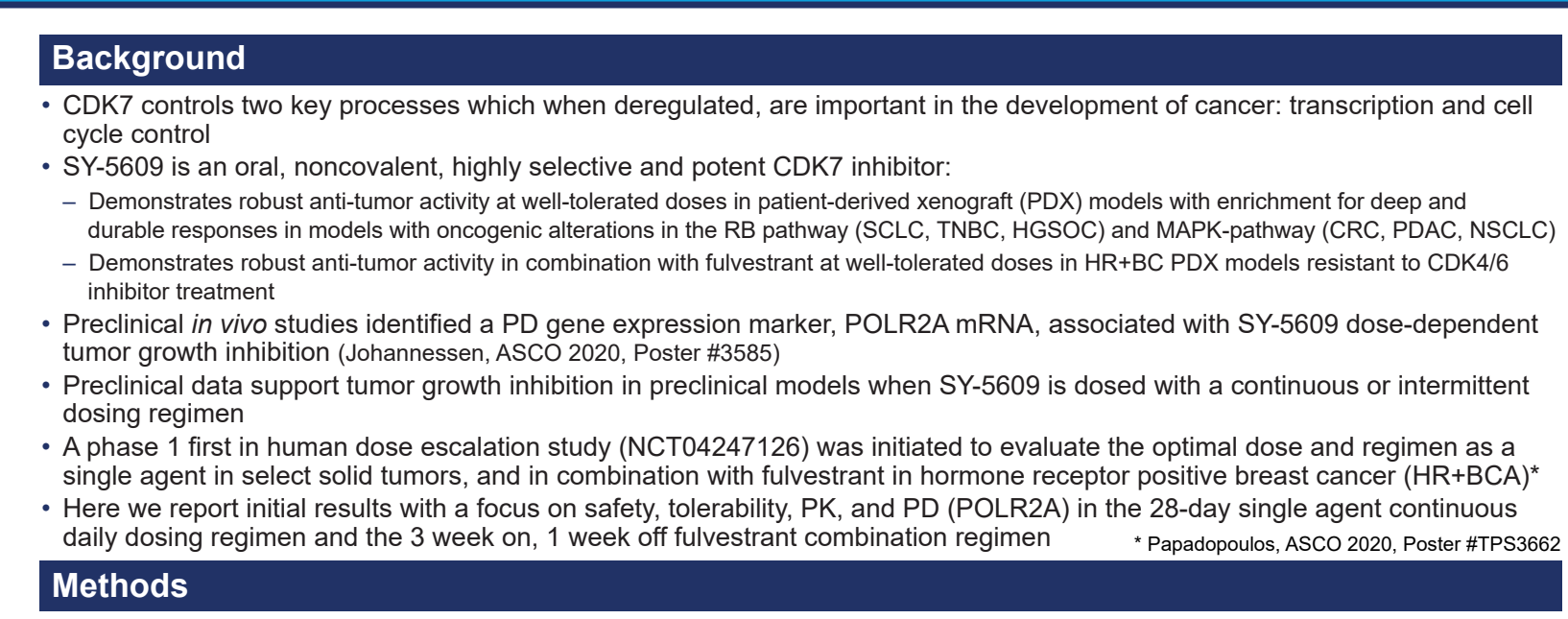

\section{Methods}

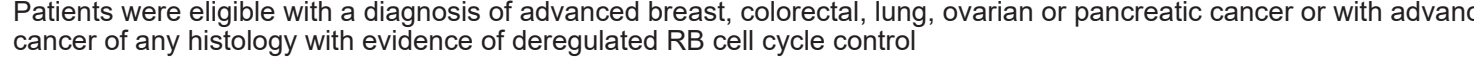

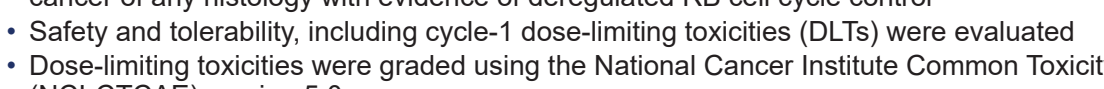

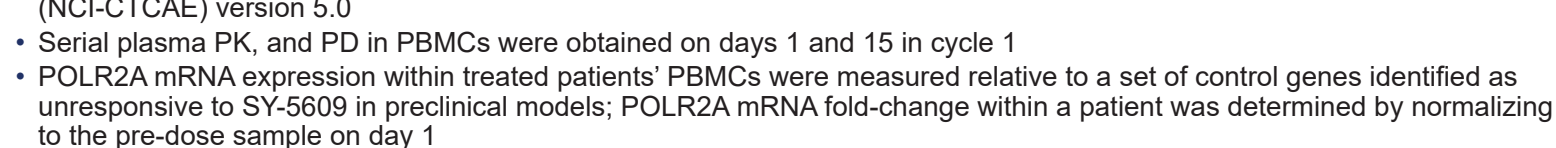
- to the pre-dose sample on day 1 . Tumor responses were assessed per RECIST version 1.1
- Data presented from August 21.2020 snapshot

\section{SY-5609-101 Study Status Summan}

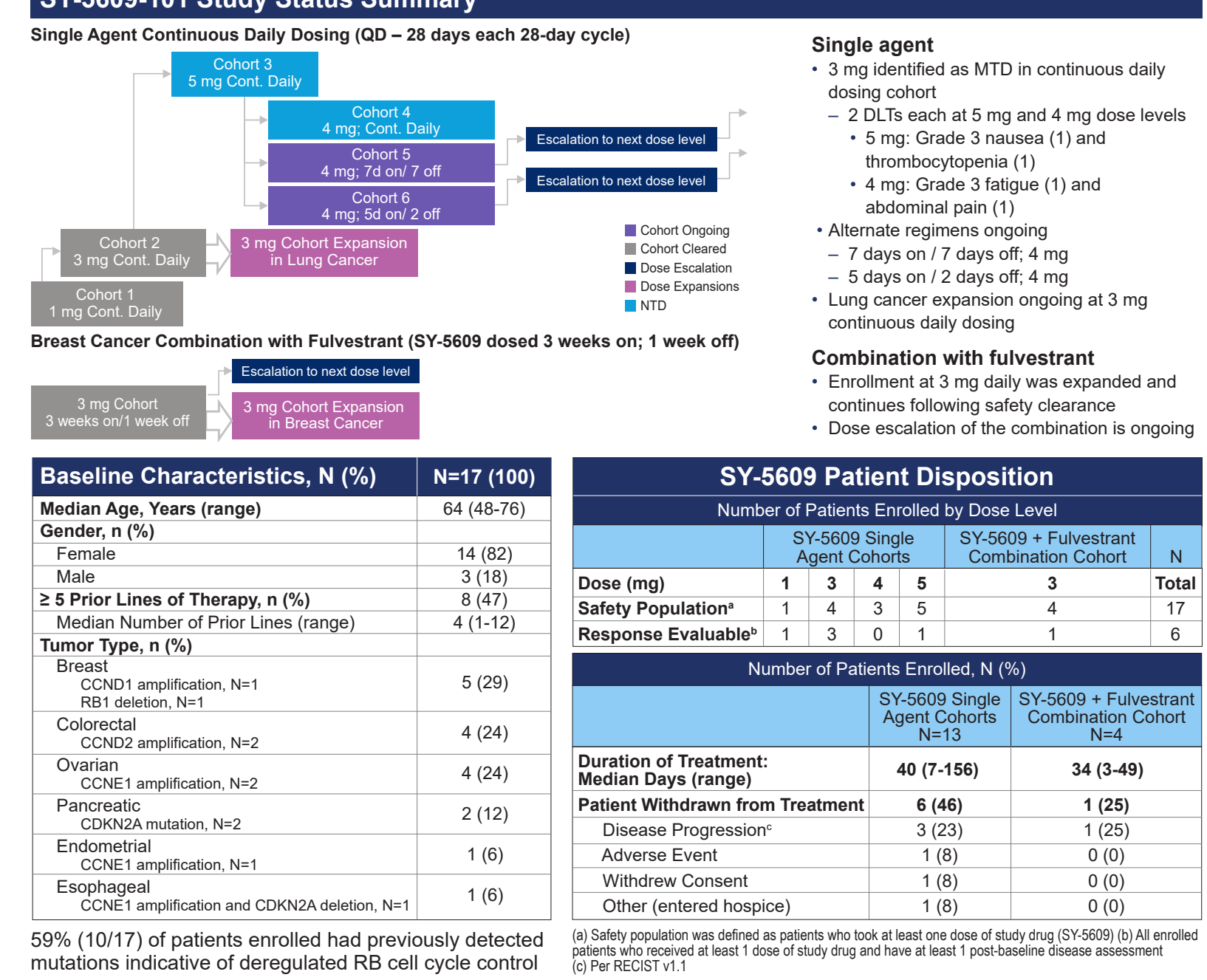

\section{SY-5609 Safety Overview}

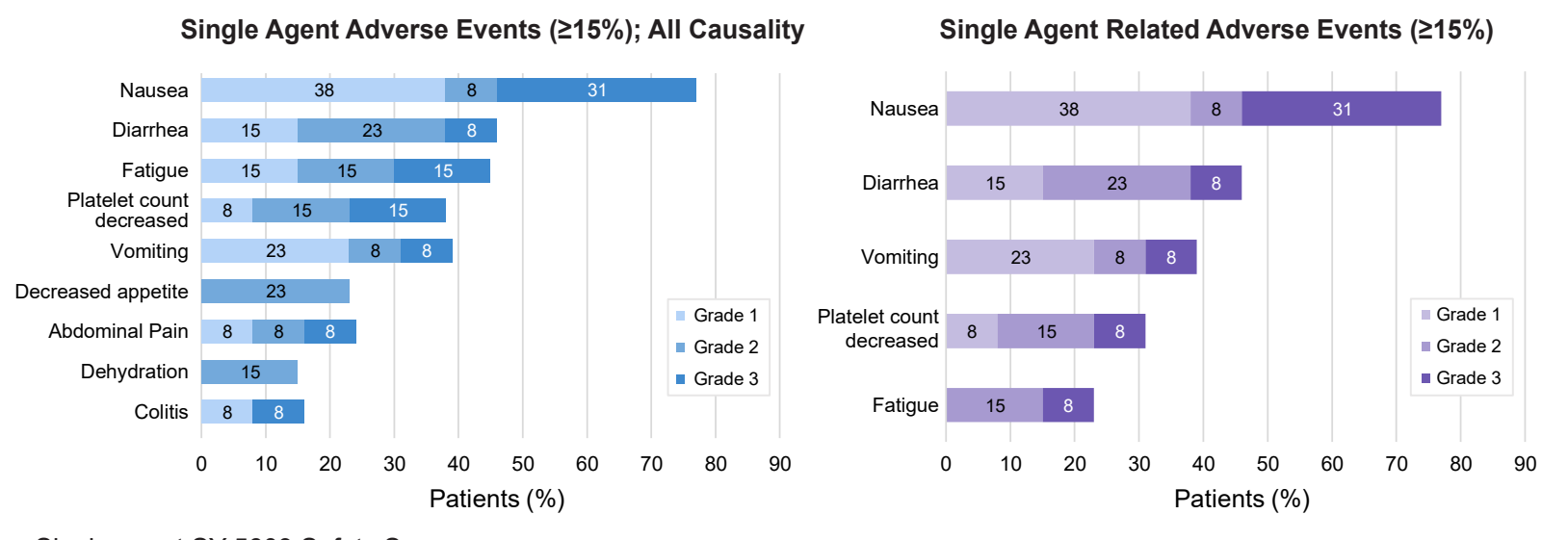

- Single agent SY-5609 Safety Summary
- The majority of reported AEs were low

- The majority of reported AEs were low grade
- The most common $A \mathrm{~S}^{*}$ were nausea, diarrhea, fatigue, platelet count decrease and vomititing

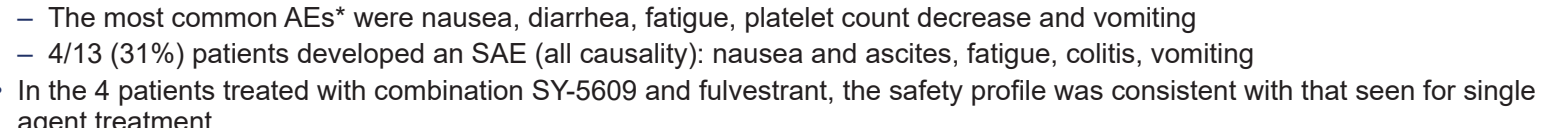

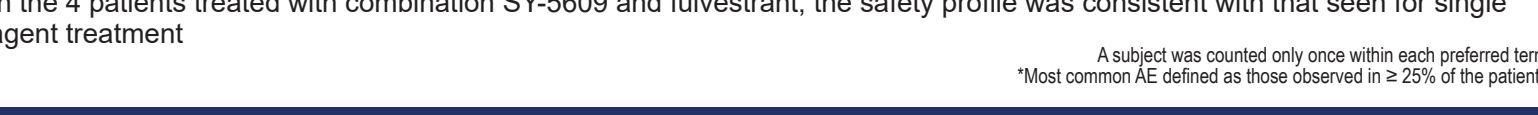

\section{Response Summary}

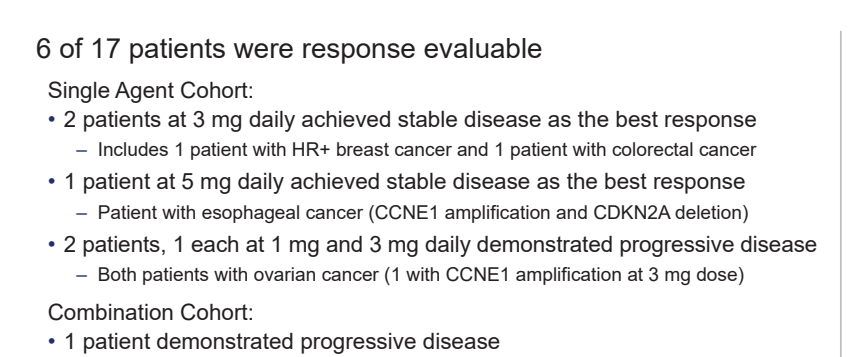

11 of 17 treated patients were not response evaluable at
the time of the data-cut

2 patients had discontinue

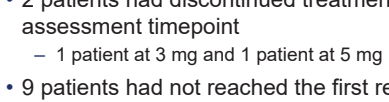

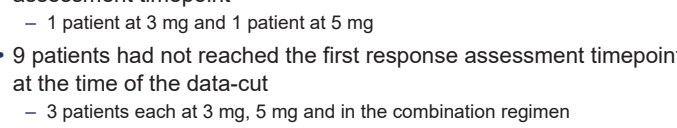
(1)

Combination Cohort:

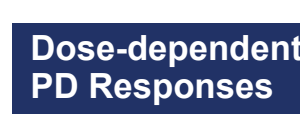

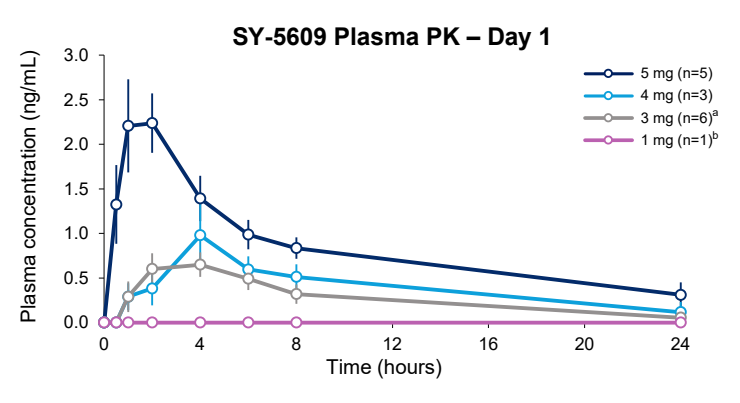

PBMC POLR2A PD - Day 1

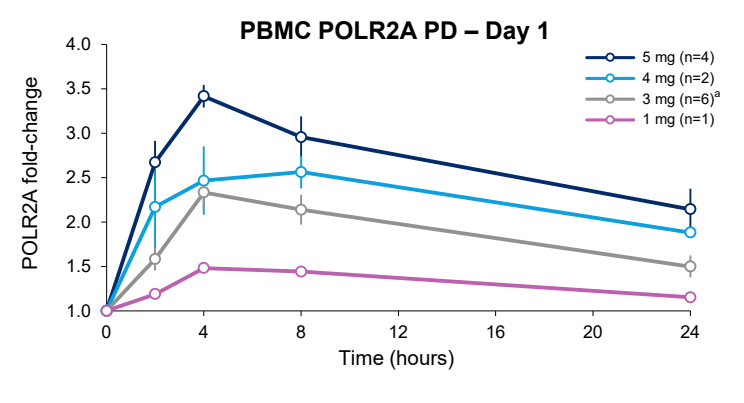

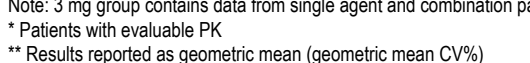

- SY-5609 exhibited approximately dose proportional PK with
moderate-high interpatient variability and minimal - SY-5609 had on half-life ats steady state $(\sim 15 \mathrm{hrs})$ compatible
with once daily dosing - Co-administration with fulvestrant had no impact on PK of - PYLLR2A PD responses measured on Day 1 across all dose
levels had dose-dependent increases over 24 hours

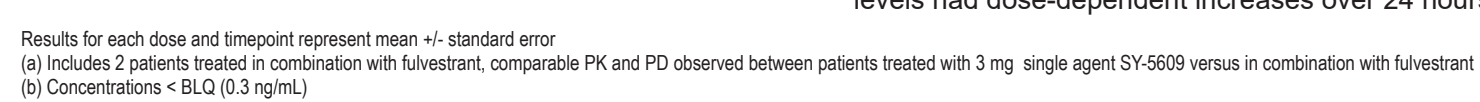

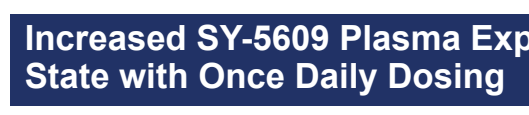
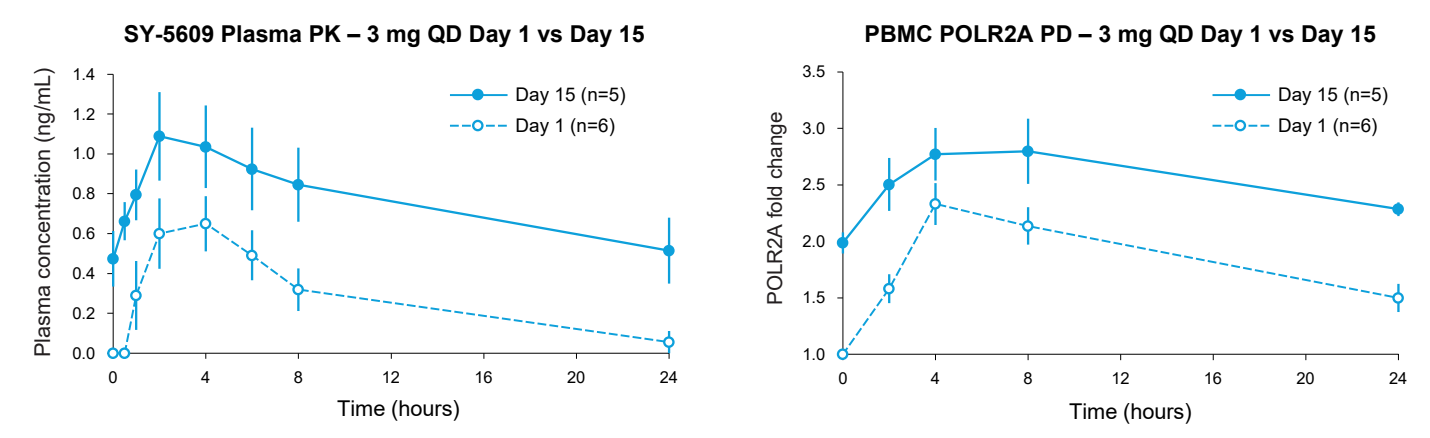

- PK and PD data were avalable at the $3 \mathrm{mg}$ continuous daily dose level to support an analysis of POLR2A PD at steady state on Day 15
- POLR2A PD responses at Day 15 were enhanced relative to Day 1, consisitent with increased SY-5609 exposure at steady state SY-5609 Dosed at $3 \mathrm{mg}$ Daily Induces POLR2A Elevations Associated with Regressions in
Preclinical Models and Target Levels of CDK7 Occupancy in Patients
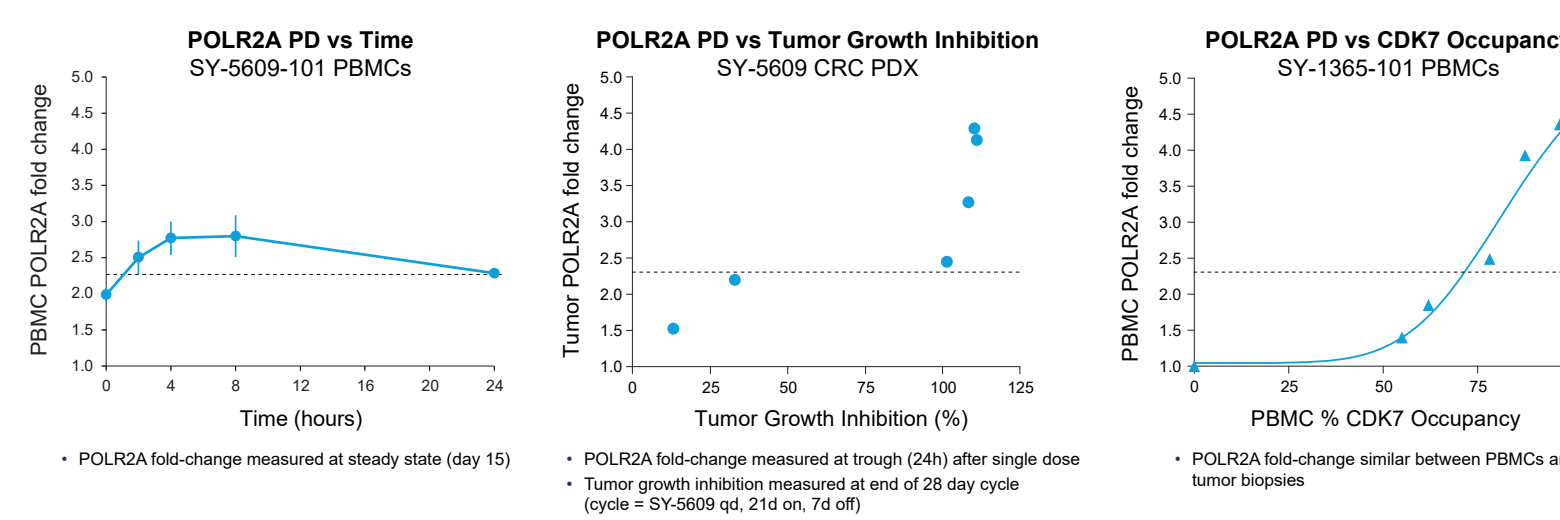

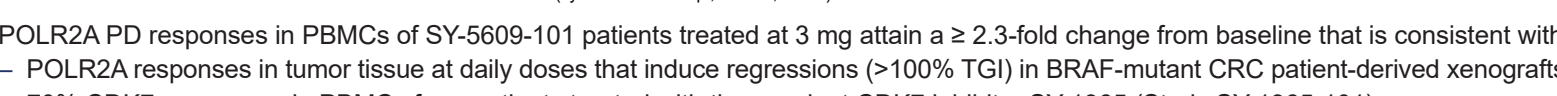

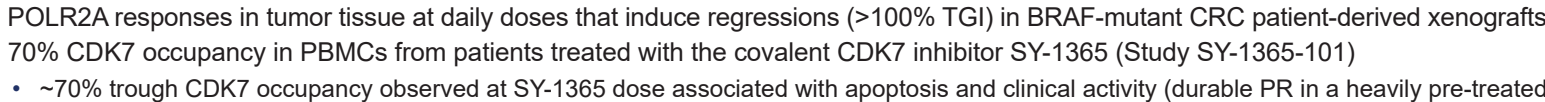

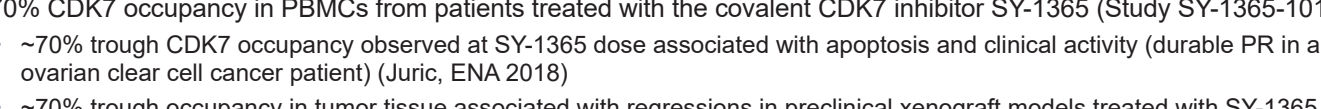

\section{Conclusions}

Administration of an Intermittent Dosing
Regimen Maintained Tumor Regressions
in Ovarian Cancer Xenografts

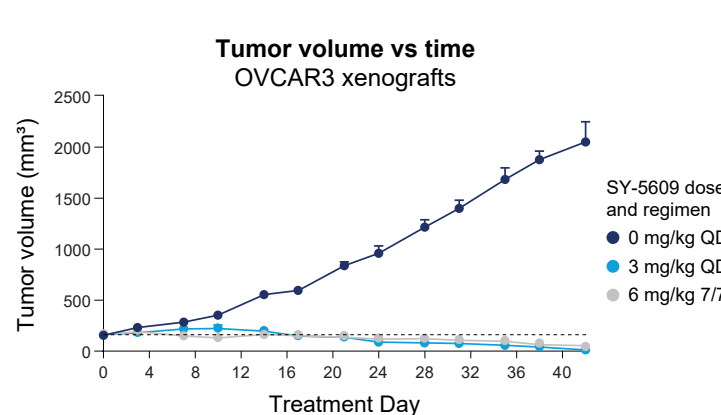

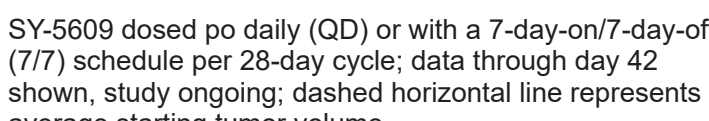

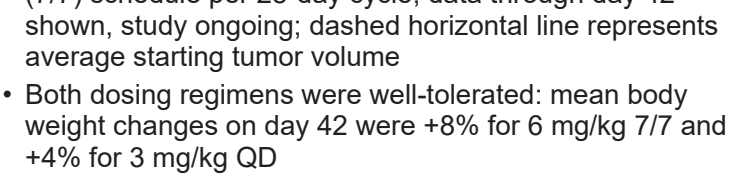

- SY-5609, a aighly selective and potent oral inhibitor of CDK7, demonstrating proofof of mechachism in patients with advancese - POLR2A PD response at $3 \mathrm{mg}$ QD reached levels associated

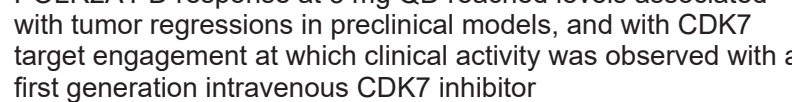
As a single agent and in combination with fulvestrant, SY-5600
exhibited approximately dose proportional PK, moderate-high

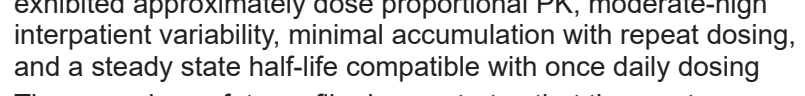
- The emerging safety profile demonstrates that the most common
AEs to date were nausea, diarnhea, fatigue, platelet count (t) continuous daily dosing sched at 3 mg
axxansion
Exans 然ansion cohorts in breast and lung cancer patients have clinical activity in more homogenous cancer patient populations - Alternate clinical dosing regimens being explored are supported
by reclinical models where tumor regressions were maintained
with internittent dosing 